Шиповская Л.П., Гемонов А.В.

\title{
ФИЛОСОФСКАЯ ИНТЕРПРЕТАЦИЯ ГЕРАЛЬДИЧЕСКИХ СИМВОЛОВ РУСИ В ПЕРИОД СМУТНОГО ВРЕМЕНИ (1598-1613 гг.)
}

Аннотация: Предпринята попытка философского анализа геральдической символики Руси периода Смутного времени. В качестве основного метода философской интерпретаиии геральдических атрибутов указанного отрезка истории нашей страны используется семиотический подход, поскольку в его рамках представляется возможным обнаружение и анализ знаково-символического базиса социальной реальности, включающей разнообразные формы совместной активности индивидов. В статье указывается, что Смутное время - это особый период в развитии российского общества, характеризующийся утратой соииальной солидарности, дезинтеграчией, дестабилизачией общественной системы. В статье авторы утверждают, что выступая знаково-символическим аспектом сочиальной жизни рубежа XVI-XVII столетий, геральдические изображения отразили как опыт исторического развития натей страны, так и стремления правителей эпохи Смутного времени удержать власть в своих руках и сформировать чувство национальной сплоченности и единства. В качестве объекта семиотического анализа в статье рассматривается символь орла, коня и всадника. Стандартный семиотический анализ с опорой на мнения ряда авторитетных философов авторы указывают на важность соииальной солидарности как приниипа социальной жизни и условия нормального развития общества и делают вывод о кризисном характере Смутного времени, который отразился в геральдике данного исторического периода определением означающего, означаемого и референта (по методологической схеме У. Эко) в статье дополняется использованием архетипической теории Юнга, а также диалектики как универсального метода философского познания. Review: The article contains an attempt of philosophical analysis of heraldic symbols of Russia at the Time of Troubles. The main method of philosophical interpretation of heraldic symbols of the above-mentioned period in the history of our state is a semiotic approach, since it allows for discovery and analysis of the balance between signs and symbols of social reality involving various forms of joint activities of individuals. It is noted in the article that the Time of Troubles is a special period in the development of the Russian society, and it is characterized with the loss of social solidarity, disintegration, destabilization of the social system. In the article the authors state that being a sign and symbolic aspect of social life at the verge of XVI-XVII centuries, the heraldic images reflect both the experience of historical development of Russia and the urge of the rulers of the Time of Troubles to hold on to the power and to form the feeling of national closeness and unity. The article includes semiotic analysis of the symbols of eagle, horse and rider. Having performed a standard semiotic analysis based upon the position of a number of authoritative philosophers, the authors point out the importance of social solidarity as a principle of social life and a condition for the normal development of the society, making a conclusion on the crisis character of the Time of Troubles, which is reflected in the heraldic symbols of this period of time, defining the passive and active meaning and the referent element based upon the methodological scheme of Umberto Eco) and this method is complemented with the use of archetypal theory of Jung, as well as dialectics, being an universal method of philosophical cognition.

Ключевые слова: Знаки и символы, смута, социальная солидарность, семиотика, орел, конь, всадник, Смутное время, Российское государство, геральдические изображения.

Keywords: Signs and symbols, troubles, social solidarity, semiotics, eagle, horse, rider, the Time of Troubles, the Russian state, heraldic images. 


\section{Политика и общество 7 (115) • 2014}

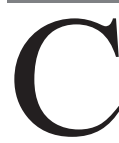

обытия, происходившие в России в конце XVI- начале XVII вв., называются «Смутным временем». В этот сложный для страны период истории один за другим менялись правители, вспыхивали мятежи и народные волнения. Российское государство было поставлено перед выбором: либо оно отстоит свою независимость, либо ее потеряет.

С точки зрения философии Смутное время - это время десолидаризации русского социума, утраты обществом необходимого для его стабильного существования и развития единства и согласованности.

Смутное время можно считать критическим периодом нашей истории, так как в то время была характерна утрата социальной солидарности, которая выступает, по нашему мнению одним из «скрепов» общественной системы, универсальным основанием социальной реальности.

Идеи о социальной солидарности как условии социальной стабильности в философии проявляются еще в теории общественного договора. О зависимости общества от благополучия индивида писал Гольбах, представитель французского материализма XVIII века. «Если общество лишает человека всех его благ, стремление к которым обусловлено его природой, или отказывает ему в том, что необходимо для самосохранения, он кончит тем, что проникнется к нему ненавистью...»'. Мало того, Гольбах продолжает, что «по мере того, как все большее и большее количество индивидов отделяет свои личные интересы от общественных, узы, связывающие объединение, слабеют и разрушаются» ${ }^{2}$.

Итак, представим, что будет, если большинство индивидов разочаруется в обществе: дестабилизация социальной системы и как последствие этого ее коренное преобразование или даже разрушение.

Общество и индивид однажды заключили контракт. При этом индивид сказал: «Помогайте мне, и я также буду оказывать вам помощь в меру моих сил; оказывайте мне содействие - и вы можете рассчитывать на содействие с моей стороны». На это общество ему ответило: «Отдай объединению свои способности и тогда мы предоставим тебе помощь, умножим твои силы, будем совместно трудиться

\footnotetext{
${ }^{1}$ Гольбах П. Об обществе // Социальная философия. Хрестоматия ч. I / сост. Арефьева, Ананьева, Арбузов - М., 1994. -c. $71-72$

${ }^{2}$ Там же
}

для твоего благополучия, облегчим трудности твоей жизни, обеспечим тебе отдых и общими усилиями отразим несчастья, которых ты страшишься, гораздо действеннее, чем это сделал бы ты сам».

Именно поэтому индивид соглашается на ограничение изначально присущей ему свободы, именно поэтому человек соотносит свою экзистенцию с экзистенциями других, именно поэтому мы говорим о бытии человека, то мы говорим не о бытии, а о со-бытии.

Социальной солидарности уделялось внимание во многих направлениях социально-философской мысли. Так, в позитивизме социальная солидарность рассматривается в двух аспектах: солидарность как порождение коллективизма и поглощение индивида обществом, и солидарность как порождение общественного разделения труда. В соответствии с этим Э. Дюркгейм в работе «О разделении общественного труда» писал о двух типах солидарности: механической и органической ${ }^{3}$.

Позитивистская трактовка социальной солидарности не является подходящей для обоснования социальной помощи терминальным больным, поскольку источником социальной солидарности в позитивизме является общество, индивид лишь слепо подчиняется социуму. В позитивизме индивид сам по себе ничего не значит, он - клетка социального организма, он не сам решает, быть ему частью общества или не быть, а его вынуждает к этому само устройство социальной жизни. При механической солидарности принципом такого устройства является коллективизм, который означает полное растворение индивидуального сознания в общественном, полное размывание индивида в общественной массе.

При органической солидарности принципом социальной жизни и основанием социальной солидарности является общественное разделение труда. Хочет индивид, этого или нет, но он выполняет те трудовые функции, которые приписаны ему обществом. А поскольку он ограничен в своих возможностях, то зависит от остальных членов общества.

Согласно взглядам позитивистов, каждый член общества играет свою роль, и если он выпадает из единой слаженной системы социального агрегата, то это негативно сказывается на функционировании и развитии последнего.

\footnotetext{
3 Дюркгейм Э. О разделении общественного труда // Западно-европейская социология XIX - начала XX веков. - М., 1996. - C. 256-309
} 
Социальная солидарность объяснялась через разделение труда не только в позитивизме, но и в марксизме. В марксистской трактовке основанием социальной солидарности является разделение труда как разрешение противоречия между тем, что материальные потребности человека множественны, а производственные возможности ограничены, поскольку каждый производит особый продукт. Именно поэтому человек стремится к согласию с другими: он производит продукт, без которого другие существовать не могут, но он также не может существовать без продуктов, производимых другими. Карл Маркс писал, что «обмен и разделение труда взаимно обусловлены. Так как каждый работает сам по себе, а его продукт есть ничто сам по себе, то он, конечно, должен не только для того, чтобы принять участие во всеобщей производственной способности, но и для того, чтобы превратить свой собственный продукт в жизненное средство для самого себя». ${ }^{4}$

Общество должно предотвращать «выпадение» человека из экономической системы, сохранять условия, необходимые для его производственной активности. Ведь человек в процессе деятельности производит общество ${ }^{5}$, но это происходит лишь в том случае, если человек получает от общества то, что ему нужно: условия для достойного существования. В этом и заключается гуманизм социальнофилософского учения Маркса. Социальная помощь направлена на сохранение достойных условий существования человека, в каких бы тяжелых жизненных обстоятельствах он не оказался. К. Маркс усматривает значение человека для общества и его сущность в деятельности, в деятельности, прежде всего, производственной. «Как само общество производит человека как человека, так и он производит общество» ${ }^{6}$. По его мнению, «практическое созидание предметного мира, переработка неорганической природы есть самоутверждение человека как сознательного - родового существа». ${ }^{7}$ Социальная помощь, таким образом, является целесообразной

\footnotetext{
${ }^{4}$ Маркс К. Критика политической экономии // Маркс К. Энгельс Ф. Собрание сочинений т. 46, ч. I. С. 101.

${ }^{5}$ Маркс К. Экономическо-философские рукописи // Маркс К., Энгельс Ф. Собрание сочинений - Т. 42 - М., 1974, с. 118

${ }^{6}$ Там же

${ }^{7}$ Маркс К. Экономическо-философские рукописи // Маркс К., Энгельс Ф. Собрание сочинений - Т. 42 - М., 1974, с. 93
}

лишь в отношении тех индивидов, кто еще способен «производить общество».

Таким образом, социальная солидарность выступает важным условием нормального функционирования социума, его развития и прогресса: без сплоченности, согласованности и единства в рамках одного социоисторического организма, каковым мы и склонны считать русское общество на конкретном отрезке его исторического пути, невозможно достижение прогресса. А именно такая ситуация сложилась на Руси в период Смутного времени, и люди, занимавшие трон, пытались всячески удержать власть в своих руках, распространив ее на все население нашей необъятнй по географическим меркам Родины.

Подобная кризисность, рассогласованность, утрата единства и попытки самозванцев, сменяющих в то время друг друга на троне, удержать власть, стабилизировать политическую ситуацию можно считать доминирующими тенденциями в социальной жизни Руси периода Смутного времени. Мы считаем, что именно эти особенности находят свое отражение и в знаково-символической формах данного периода, в том числе и в геральдике. Другими словами, геральдика Смутного времени является знаково-символическим отражением социальной жизни того времени.

Для проверки указанного предположения о выражении кризисных тенденцией социальной жизни периода Смутного времени в истории Руси мы из всего многообразия философских подходов выбрали семиотический, так как он позволяет сформировать особый - семиологический - угол зрения на социальную жизнь Руси периода Смутного времени. Данный подход заключается в вычленении и анализе знаково-символического аспекта жизни русского социума, изучении воздействия знаков и символов данного общества на сознание и поведение составляющих его индивидов. При разработке данного методологического подхода мы опирались на семиологическую теорию итальянского философа современности Умберто Эко. Геральдические символы в указанном теоретико-методологическом контексте составляют значимый и одновременно недостаточно исследованный сектор семиосферы Руси периода Смутного времени.

Значимость семиотического подхода в данном исследовании подтверждается также тем фактом, что мировоззрение личности во многом детермини- 


\section{Политика и общество 7 (115) • 2014}

руется его визуальной контактом с внешним миром. В опыте познания действительности личность опирается как на лингвистические, так и на визуальные репрезентативные системы. Доминирующие знаки и символы, а также и специфика их представленности, в том числе и в геральдике, на наш взгляд, оказывает воздействие на миропонимание.

Как и любая символика, геральдические символы представляют собой важный пласт мировоззрения, поскольку в них в символической форме отражаются особенности отношения к миру представителей той исторической эпохи, в которую они возникли. Выделенный нами мировоззренческий аспект рассматриваемого феномена культуры делает актуальным его рассмотрение с позиций универсальных мировоззренческих концепций и подходов, то есть его философскую интерпретацию.

Важнейшим инструментом семиотического анализа является представление о связи между символом (означающим) и эффектом в сознании человека (означаемым) и о том, как эта связь, называемая референцией и существующая в абстрактно-понятийной сфере, влияет на поведение индивидов. Несомненным нам представляется тот факт, что «знаки приводят наши мысли в порядок всеми возможными способами, но не ограничивают наше творчество и познание» ${ }^{8}$.

Методологическую основу нашего исследования составит семиотическая схема, на которой отражены указанные связи.

\section{Означаемое}

(понятие или концепт)

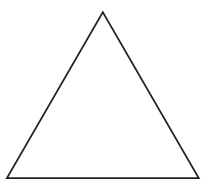

Означающее

(знак)

Референт

(предмет в реальности)

При этом, предметом семиотического анализа выступает связь между означающим и означаемым, то есть эффекты, порождаемые знаками и

\footnotetext{
8 Эко. У. Отсутствующая структура. Введение в семиологию - СПБ.: ТОО ТК «Петрополис», 1998. - 432 с. С. 153
}

символами в сознании и поведении людей. Знаки сами по себе изучаются в рамках иного, семантического анализа. При этом, важно отметить, что связь между знаком и референтом может отсутствовать в силу ирреальность последнего.

Рассмотрим ряд геральдических символов периода Смутного времени.

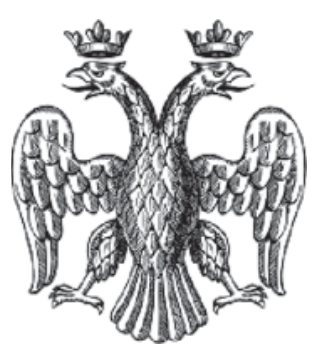

Символ 1. Двуглавый орел на печати цุаря Бориса Годунова (1599 г.)

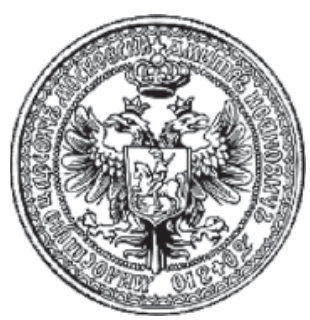

Символ 2. Двуглавый орел на печати Лжедмитрия I (1605 г.)

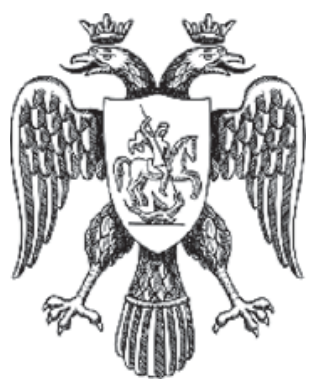

Символ 3. двуглавый орел на печати Лжедмитрия II (1609 2.).

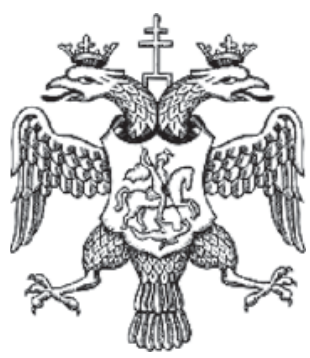

Символ 4. Гербовый двуглавый орел (1613 год) 


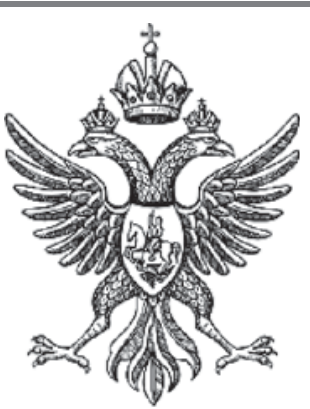

Символ 5. Двуглавый орел на карте России (1614 2.)

На печати Лжедмитрия, датируемой 1604 г. орел изображен, увенчанный тремя коронами, а всадник на груди орла - обращенным в правую геральдическую сторону. Однако после свержения Лжедмитрия орел снова стал изображаться увенчанным двумя коронами, а всадник - обращенным в левую сторону. Только после избрания на царство 21 февраля 1613 г. Земским собором Михаила Федоровича Романова, в 1625 г. на малой государственной печати двуглавый орел был изображен увенчанным тремя коронами, которые, по мнению одних, символизировали Святую Троицу, других - Великую, Малую и Белую Русь.

Основным элементом на представленных изображениях них выступает двуглавый орел. Если применить схему семиотического анализа У. Эко, то означающим будет изображение орла, означаемым будут служить те смыслы, которыми наделяет данное изображение человек, его визуально воспринимающий, и на основании чего формирует особое отношение к носителям данного символа. Что касаемо референта, то это орел как часть природной действительности. Но необходимо признать, что «перекочевав» на геральдическое изображение орел приобрел фантастические черты, прежде всего еще одну голову. Такое преображение, на наш взгляд, было сделано с целью усиления символического аспекта. Иными словами, орел как часть реальности, орел как часть субъективного мира индивида, воспринимающего анализируемое геральдическое изображение орла, не является простым отображением орла как части объективной действительности.

Иными словами, на представленных геральдических изображениях герб является символом или означающим, референтом в данном случае является орел как элемент объективной действительности, который воспроизведен на гербе в схематической форме, означаемым выступают те представления, мысли, возникающие в сознании человека, видящего данный герб. Если рассматривать изображение в качестве знака, то означаемое сведется к мыслям, возникающим в сознании воспринимающего данный визуальный образ. Но данный визуальный образ представляет собой не просто знак орла, а знак, скрывающий глубинный геральдический смысл, и именно эта смысловая наполненность данного образа позволяет отнести его к разряду символов.

По мнению А.Г. Силаева, символический образ орла был характерен для нашей страны и ранее $^{9}$. Так, орлиные изображения применялись как в народных узорах, так и на княжеских плащах и щитах Ярослава, Бориса и Глеба. В мифическом мировоззрении славян орел был символом Перуна, он выступал защитником князя и княжеской дружины еще с дохристианского периода истории нашей страны. Помимо использования на гербах, двуглавый орел служил нумизматическим изображением у монголов (монеты хана Джанибека в сер. XV в.) и у тверского князя Михаила Борисовича в 70-х гг. XV в.

Если обратиться в символическому значению орла в контексте мировой культуры, то он с глубокой древности служил образом царствования и главенства, так как в мире птиц орел занимает верховенствующее положение. Орел в мифологическом синкретичном сознании как птица, летающая выше остальных пернатых существ и наиболее приближенная к источнику тепла и жизни на земле, был связан непосредственно с Солнцем. Вследствие этого, орел для наших предков символизировал божьего посланника, посредника, связующего два мира - людей и богов. Так, в древнегреческой мифологии орел являлся одним из олицетворений верховного бога Зевса. Орел использовался и в военногосударственной символике экспансионистского Рима. С отходом от мифологических представлений, орел у большинства народов сохранился в качестве символического образа мудрости, храбрости, высокой нравственности и силы. Помимо данного значения, орел, вооруженный острыми когтями, является символом борьбы с несправедливостью и с врагами.

9 Силаев А.Г. Истоки русской геральдики - М.: ФАИРПРЕСС, 2003. 240 с. c. 61 


\section{Политика и общество 7 (115) • 2014}

Таким образом, использование орла в качестве геральдической символики правителями Руси Смутного времени Борисом Годуновым и двумя Лжедмитриями можно расценить как стремление продемонстрировать в знаково-символической форме законность претензий на власть, диктата воли и силу государственного принуждения. Визуальное восприятие данного символа на геральдических знаках должно было формировать у народа соответствующее почтительное отношение к власти в столь нестабильный период истории нашей страны. Конкретизируем представленную выше схему.

Почтительное отношение к носителям символа, уважение и благоговение, вплоть до трепета царской печати, как знак или означающее

Орел, как референт знака или часть реальности

нимба вокруг головы означало светский характер всадника, то есть символическое изображение князя. Как указывает Соболева Н.А., подобная «традиция может быть основой восприятия вооруженного всадника как князя, а позднее - царя» ${ }^{11}$.

С точки зрения юнгианства, конь, как и всадник, представляют собой древние солярные символы, встречающиеся в мифологических системах большинства народов, в том числе и в мифах и верованиях древних славян. Через данный архетип в коллективном бессознательном наших предков было зафиксировано представление о вооруженном всаднике на коне как олицетворении мощи и могущества ${ }^{12}$. На выбранных нами для интерпретации геральдических изображениях «Мощь конской фигуры является как бы могучим подножием фигуры героя властелина» ${ }^{13}$.

С конем у славян были связаны представления о жизни и смерти, о смене времен года, особенно о весне, когда

Помимо семиотического подхода при рассмотрении символа орла вполне применим, по нашему мнению, и психоаналитический подход, согласно которому влияние символов осуществляется на уровне не сознания, а на уровне коллективного бессознательного. Орел в данном случае выступает архетипическим образом, означающим, согласно В.П. Самохвалову, «восприятие и внимание, «орлиный глаз». сознательность. высокий полёт ума и духа. мужской дух энтузиазма. доминирование» ${ }^{10}$.

Иными словами, геральдическое изображение орла при подобном его рассмотрении оказывает воздействие на глубинные бессознательные слои психики людей, его воспринимающих, вследствие чего формируется соответствующее отношение к носителям данного символа (правителям эпохи Смутного времени).

На всех представленных изображениях, помимо орла, присутствует всадник на коне, повергающий змея. Вооруженный всадник на коне означает силу, выносливость и скорость, то есть преимущества в физических качествах: силы, ловкости и т.д. Также данный образ символизирует гарантированность охраны и отеческого покровительства. Отсутствие

${ }^{10}$ Самохвалов В. П. Психоаналитический словарь и работа с символами сновидений и фантазий. - Симферополь: СОHAT, 1999. - c. 175 природа возрождается к жизни, и осени когда природа увядает. Так, у славян издавна существовал обряд проводов весны. Исходным ключевым моментом проводов весны было жертвоприношение коня. Принося в жертву животное, наши предки верили, что его душа отправляется на небо, и тем самым пытались задобрить богов для привлечения плодородия, счастья и удачи. Подобные ритуалы также можно встретить и у древних индусов, германцев и скандинавов, что можно объяснить единым центром происхождения всех этих народов.

Таким образом, уверенность в могуществе носителя данного символа - князя не формировалась постепенно и осознанно, скорее это происходило на подсознательном уровне. Человек как представитель русской культуры и носитель русской ментальности, причастный к коллективному бессознательному, включающему в себя целый

\footnotetext{
${ }^{11}$ Соболева Н. А. Очерки истории российской символики. От тамги до символов государственного суверенитета - М.: Языки славянских культур: Знак, 2006. - 487 с. с. 106

${ }^{12}$ Шиповская Л.П., Гемонов А.В. Философская интерпретация геральдических символов Руси периода монголо-татарского ига. М.: 2013. с. 1707-1718. с. 1719

${ }^{13}$ Иванов М.К. Образ всадника в искусстве: иконографический архетип. Интернет-ресурс. Режим доступа: http://www. ibif.org.ru/articles/nachalo01/01-03.pdf C. 32
} 
ряд архетипических образов, в том числе и образ всадника, видя указанный символ на печати, сразу осознавал превосходство и властный статус князя.

Всадник, если придерживаться юнгианской концепции, в качестве символического компонента коллективного бессознательного присутствует в отечественной культуре и по сей день, проявляя себя не только в искусстве, но и в таком феномене индивидуальной психики, как сновидения. Так, если обратиться к мнению одного из отечественных постъюнгианцев В.П. Самохвалова, то лошадь символизирует энергию ${ }^{14}$. Если рассматривать энергию в универсальном, предельно обобщенном значении этого слова, то энергия будет означать жизненную силу, порыв, импульс, благодаря которому его носитель ведет за собой окружающих его людей. Так и правитель, наделенный властными полномочиями, мог реализовывать их только в том случае, если обладал достаточной доля этого жизненной энергий, духовной силой, способностью вести за собой других людей.

Изображенный всадник - это Георгий Победоносец. Изображение Святого Георгия указывает на значимость для наших предков религиозной веры, проявляющейся в том числе и в вере в святых защитников и покровителей, способных прийти на помощь в трудные минуты жизни не просто отдельных людей, а целых городов. Особенно это было важно во время Смуты, когда люди испытывали чувства смятения, страха, неуверенности в завтрашнем дне.

Таким образом, рассмотренные нами геральдические символы орла, коня и всадника отражают стремление правителей периода Смуты создать в народе уверенность в справедливости и обоснованности их претензий на власть. Символ Георгия Победоносца, олицетворял, на наш взгляд, защищенность и единство на основе общей православной веры. Для русского народа подобное мироощущение, основанное на соборности и сплоченности, являлось исторической традицией, восходящей к дохристианским верованиям и традициям древних славян.

«Для языческого миросозерцания и мироощущения характерно то, что человек не противопоставлял себя космосу, природе, а растворялся в них, ста-

${ }^{14}$ Самохвалов В. П. Психоаналитический словарь и работа с символами сновидений и фантазий. - Симферополь: СОHAT, 1999. - c. 184 новясь таким же целым, как и они. Ощущая «себя принадлежностью целого», человек закреплял в общинных традициях нормы своего существования не только в природе, но и в мире людей: общине или роде, вследствие этого род или община гарантировали ему защиту и поддержку» ${ }^{15}$.

Идентичность у древних славян означала чувство принадлежности к роду, а затем - к общине, значит в то время имела место общинная или родовая идентичность.

С формированием русского государства формуется потребность возникновения национального единства, хотя она формируется не сразу. На наш взгляд, национальная сплоченность проявляла себя в те периоды отечественной истории, которые были сопряжены с трудностями и лишениями, перенести которые без национального единения было практически невозможно. К таким событиям можно отнести, прежде всего борьбу с крестоносцами, борьбу с кочевниками и с монголо-татарским игом, борьбу с польскими интервентами во время смуты.

Мы считаем, что окончательно национальная идентичность в нашей стране сформировалась именно с воцарением Михаила Романова на царском престоле. Именно это событие ознаменовало окончание Смутного Времени и прекращение раздоров между жителями русской земли. В это время пришло осознание принадлежности к русскому народу и русской земле, чувство общности и единства, причем не только территориального, но и культурного, религиозного, духовного. Из Смуты русский народ вынес горький исторический урок: разрозненность в народе ведет к его ослаблению и угрозе исчезновения.

\section{Библиография:}

1. Антипов М.А. Традиции взаимопомощи как аспект общественных отношений древних славян // Этногенез и ранняя история народов Ев-

\footnotetext{
${ }^{15}$ Антипов М.A. Традиции взаимопомощи как аспект общественных отношений древних славян // Этногенез и ранняя история народов Евразии: Материалы международной научно-практической конференции (Пенза-Прага, 5-6 апреля 2010 г.) - Пенза: ООО Научно-издательский центр «Социосфера», 2010. Интернет-ресурс: http://www.sociosphera.com/ publication/conference/2010/74/tradicii_vzaimopomowi_kak_ aspekt_obwestvennyh_otnoshenij_drevnih_slavyan/
} 


\section{Политика и общество 7 (115) • 2014}

разии: Материалы международной научно-практической конференции (Пенза-Прага, 5-6 апреля 2010г.)-Пенза:ОООНаучно-издательскийцентр «Социосфера», 2010. Интернет-ресурс: http:// www.sociosphera.com/publication/conference/ 2010/74/tradicii_vzaimopomowi_kak_aspekt_ obwestvennyh_otnoshenij_drevnih_slavyan/

2. Белецкий С.Д. Древнейшая геральдика Руси // «Повесть временных лет». СПб., Вита Нова, 2012. стр. $431-463$.

3. Бергер П., Лукман Т. Социальное конструирование реальности. Трактат по социологии знания-М.: «Медиум», 1995 г. - 323 с.

4. Галанин А.В. Арийские традиции // Вселенная живая [Электронный ресурс] - Владивосток, 2012-2013. Адрес доступа:http:/ukhtoma. $\mathrm{ru} /$ traditions $1 . \mathrm{htm}$

5. Гегель В. Г. Ф. Энциклопедия философских наук - В 3 частях. Ч. 3 Философия духа - М.: Мысль, 1974 г.

6. Гольбах П. Об обществе // Социальная философия. Хрестоматия ч. I / сост. Арефьева, Ананьева, Арбузов-М., 1994. - с. 71-72

7. Дюркгейм Э. О разделении общественного труда // Западно-европейская социология XIXначала ХХ веков. - М., 1996. - С. 256-309

8. Иванов М.К. Образ всадника в искусстве: иконографический архетип. Интернет-ресурс. Режим доступа: http://www.ibif.org.ru/articles/ nachalo01/01-03.pdf C. 32

9. Маркс К. Критика политической экономии // Маркс К. Энгельс Ф. Собрание сочинений т. 46, ч. I. С. 101.

10. Маркс К. Экономическо-философские рукописи // Маркс К., Энгельс Ф. Собрание сочинений - T. 42 - М., 1974, с. 118

11. Самохвалов В. П. Психоаналитический словарь и работа с символами сновидений и фантазий. Симферополь: СОНАТ, 1999. - 230 с.

12. Силаев А.Г. Истоки русской геральдики - М.: ФАИР-ПРЕСС, 2003. 240 с. с. 61

13. Соболева Н. А. Очерки истории российской символики. От тамги до символов государственного суверенитета-М.: Языки славянских культур: Знак, 2006. - 487 с. с. 106

14. Шиповская Л.П., Гемонов А.В. Феноменология русской геральдики IX-XIV веков. Гуманитарные, социально-экономические и общественные науки. - М.: 2013. с. 41-51
15. Шиповская Л.П., Гемонов А.В. Философская интерпретация геральдических символов домонгольсой Руси. Политика и общество. - М.: 2013. с. $1429-1452$

16. Шиповская Л.П., Гемонов А.В. Философская интерпретация геральдических символов Руси периода монголо-татарского ига. М.: 2013. с. 1707-1718

17. Шюц А. О множественности реальностей // Социологическое обозрение Том 3. № 2. 2003. C. 2-34.

18. Юнг К.Г. Душа и миф: шесть архетипов. Пер. с англ.- К.: Государственная библиотека Украины для юношества, 1996. - 384 с

19. Юнг К.Г. Человек и его символы - М.: Серебряные нити, 2011. 352 с.

20. Эко. У. Отсутствующая структура. Введение в семиологию - СПБ.: ТОО ТК «Петрополис», 1998. $-432 \mathrm{c}$.

21. Ottfried Neubecker Heraldry: Sources, Symbols and Meaning. Tiger Books International (1997). 288 pages.

22. Schütz Alfred Scheler's Theory of Intersubjectivity and the General Thesis of the Alter Ego»// Philosophy and Phenomenological Research, March, 1942, c. 323-347

23. Shipovskaya L.P. Gemonov A.V. Phänomenologie des russischen Heraldik IX-XIV Jahrhundert. Science and education. P. 284-293.

24. «The quest for meaning». University of Toronto Press Incorporated, 2007, Toronto Buf-folo London. C. 153

\section{References (transliteration):}

1. Antipov M.A. Traditsii vzaimopomoshchi kak aspekt obshchestvennykh otnoshenii drevnikh slavyan // Etnogenez i rannyaya istoriya narodov Evrazii: Materialy mezhdunarodnoi nauchno-prakticheskoi konferentsii (Penza-Praga, 5-6 aprelya 2010 g.) - Penza: OOO Nauchno-izdatel'skii tsentr «Sotsiosfera», 2010. Internet-resurs: http://www. sociosphera.com/publication/conference/2010/74/ tradicii_vzaimopomowi_kak_aspekt_obwestvennyh_otnoshenij_drevnih_slavyan/

2. Beletskii S.D. Drevneishaya geral'dika Rusi // «Povest' vremennykh let». SPb., Vita Nova, 2012. str. $431-463$. 
3. Berger P., Lukman T. Sotsial'noe konstruirovanie real'nosti. Traktat po sotsiologii znaniya-M.: «Medium», 1995 g. - 323 s.

4. Galanin A.V. Ariiskie traditsii // Vselennaya zhivaya [Elektronnyi resurs] - Vladivostok, 2012-2013. Adres dostupa:http://ukhtoma.ru/traditions1.htm

5. Gegel' V. G. F. Entsiklopediya filosofskikh nauk V 3 chastyakh. Ch. 3 Filosofiya dukha-M.: Mysl', $1974 \mathrm{~g}$.

6. Gol'bakh P. Ob obshchestve // Sotsial'naya filosofiya. Khrestomatiya ch. I / sost. Aref'eva, Anan'eva, Arbuzov-M., 1994. - s. 71-72

7. Dyurkgeim E. O razdelenii obshchestvennogo truda // Zapadno-evropeiskaya sotsiologiya KhIXnachala KhKh vekov. - M., 1996. - S. 256-309

8. Ivanov M.K. Obraz vsadnika $v$ iskusstve: ikonograficheskii arkhetip. Internet-resurs. Rezhim dostupa: http:// www.ibif.org.ru/articles/nachalo01/01-03.pdfS. 32

9. Marks K. Kritika politicheskoi ekonomii // Marks K. Engel's F. Sobranie sochinenii t. 46, ch. I. S. 101.

10. Marks K. Ekonomichesko-filosofskie rukopisi // Marks K., Engel's F. Sobranie sochinenii - T. 42 M., 1974, s. 118

11. Samokhvalov V. P. Psikhoanaliticheskii slovar' i rabota s simvolami snovidenii i fantazii. - Simferopol': SONAT, 1999. - $230 \mathrm{~s}$.

12. Silaev A.G. Istoki russkoi geral'diki - M.: FAIRPRESS, 2003. 240 s. s. 61

13. Soboleva N. A. Ocherki istorii rossiiskoi simvoliki. Ot tamgi do simvolov gosudarstvennogo su-
vereniteta-M.: Yazyki slavyanskikh kul'tur: Znak, 2006. -487 s. s. 106

14. Shipovskaya L.P., Gemonov A.V. Fenomenologiya russkoi geral'diki IX-XIV vekov. Gumanitarnye, sotsial'no-ekonomicheskie i obshchestvennye nauki. - M.: 2013. s. 41-51

15. Shipovskaya L.P., Gemonov A.V. Filosofskaya interpretatsiya geral'dicheskikh simvolov domongo1'soi Rusi. Politika i obshchestvo. - M.: 2013. s. 1429-1452

16. Shipovskaya L.P., Gemonov A.V. Filosofskaya interpretatsiya geral'dicheskikh simvolov Rusi perioda mongolo-tatarskogo iga. M.: 2013. s. 1707-1718

17. Shyuts A. O mnozhestvennosti real'nostei // Sotsiologicheskoe obozrenie Tom 3. № 2. 2003. S. 2-34.

18. Yung K.G. Dusha i mif: shest' arkhetipov. Per. s angl.- K.: Gosudarstvennaya biblioteka Ukrainy dlya yunoshestva, 1996. - $384 \mathrm{~s}$

19. Yung K.G. Chelovek i ego simvoly - M.: Serebryanye niti, 2011. $352 \mathrm{~s}$.

20. Eko. U. Otsutstvuyushchaya struktura. Vvedenie v semiologiyu - SPB.: TOO TK «Petropolis», 1998. $-432 \mathrm{~s}$.

21. Schütz Alfred Scheler's Theory of Intersubjectivity and the General Thesis of the Alter Ego»// Philosophy and Phenomenological Research, March, 1942, c. 323-347

22. Shipovskaya L.P. Gemonov A.V. Phänomenologie des russischen Heraldik IX-XIV Jahrhundert. Science and education. P. 284-293. 